\title{
A NOTE ON THE TREATMENT OF LEPROMATOUS ULCERS
}

E. Muir.

Ulcers in leprosy are of two kinds: lepromatous and trophic. My experience in India showed that trophic ulcers were by far the more common of these two. An investigation of all ulcers in the large leprosarium at Purulia showed only between one and two per cent to be bacteriologically positive, the rest being of a trophic nature resulting from affection of the nerve supply. On coming to the Trinidad leprosarium at Chacachacare $\mathrm{I}$ was astonished to find that the great majority of ulcers are of a lepromatous nature, that is, due to the breaking down of nodules and diffuse leproma. These are full of masses of bacilli which are constantly shed off from the surface. The treatment of these ulcers was a problem. The sisters who dress the wounds spent a large part of their time in dressing these constantly discharging wounds. The patients, loaded with dressings and bandages become immobilised and bedridden and their limbs, and especially their fingers, become stift and atrophied.

Reading an article by Ross and Hulbert on the treatment of air battle burns with silver nitrate, tannic acid and gentian violet* I tried this method with these ulcers. The results obtained were

* Treatment of burns by silver nitrate, tannic acid and gentian violet, by J. H. Ross and K. F. Hulbert. Brit. Med. Jl. No. 4168, Nov. 23. I940, p. 702 . 
highly satisfactory. After a few applications the discharge was controlled, and in many cases it was found possible to do without dressings or to apply only a loose cloth covering. Septic absorption ceased. The patients felt much more comfortable. They were able to move their limbs and especially their fingers and thus avoid one of the chief causes of atrophy and deformity. A considerable amount of the valuable time of the staff was saved and the danger of spreading infection was considerably lessened.

The treatment, as slightly modified, consists in painting first with a one per cent solution of gentian or methyl violet in alcohol, then with a ten per cent solution of silver nitrate in distilled water, and, lastly, with a fifteen per cent solution of tannic acid in water. On the first day this is repeated three or four times, but in most cases after the first day one painting, either with tannic acid alone, or with the dye solution followed by tannic acid, is sufficient. The patients particularly appreciate the treatment of the lips and the face in this way, parts to which it is difficult to apply cloth dressings. Many ulcers which had remained discharging for weeks at once began to heal up, and the improvement in the general health and the comfort and cheerfulness of the patients was remarkable. I can strongly recommend this very simple and effective form of treatment. 